\title{
BRAF Mutation in Papillary Thyroid Microcarcinoma: The Promise of Better Risk Management
}

\author{
Mingzhao Xing, MD, PhD \\ Department of Medicine, Division of Endocrinology and Metabolism, The Johns Hopkins University School of Medicine, \\ Baltimore, MD
}

How to manage risk in cases of papillary thyroid microcarcinomas (PTMC), defined as papillary thyroid carcinomas (PTC) of size $\leq 1.0 \mathrm{~cm},{ }^{1}$ has been controversial. Conventional wisdom dictates that these are low-risk cancers that are virtually free of mortality and should therefore be conservatively managed. Also in support of conservative management of PTMC are the potentially adverse outcomes of aggressive treatments, such as surgical damage to the recurrent laryngeal nerve and parathyroid glands from thyroid surgery and the development of second primary cancers from radioiodine treatments. ${ }^{2,3}$ It is even acceptable in some practices to forgo treatments of patients with PTMC. ${ }^{4}$ On the other side of the coin, however, is the well-recognized risk that PTMC can progress with a significant recurrence rate and even mortality in some patients. ${ }^{5-7}$ This is true particularly in the presence of highrisk clinicopathological factors that are classically known to be associated with a poor prognosis in conventional thyroid cancers. These include extrathyroidal extension, lymph node metastasis, and high TNM stages. ${ }^{8-12}$ Given these divided results, it appears that a subgroup of PTMC is inherently aggressive and predestined to progress. Although opinions often differ on how to manage PTMC, ${ }^{6,7}$ there is little argument that the subgroup of patients with PTMC with high potential for poor prognosis should receive relatively aggressive initial treatments (e.g., total thyroidectomy, central neck dissection, or radioiodine ablation as opposed to lobectomy, no neck dissection, or no radioiodine ablation, respectively) and vigilant follow-up for disease recurrence after initial treatments. The challenge, however, often lies in the difficulty of identifying this subgroup of PTMC based on the classical

(C) Society of Surgical Oncology 2009

Published Online: 22 January 2009

M. Xing, MD, PhD

e-mail: mxing1@jhmi.edu clinicopathological criteria, particularly preoperatively, when the pathological characteristics of the tumor are virtually unknown. Therefore, it is often not a straightforward task to determine the appropriate level and extent of the initial treatment for an individual patient with PTMC that has been identified ultrasonographically and confirmed cytologically.

In recent years, the T1799A BRAF mutation has emerged as a promising prognostic factor in the risk stratification of PTC. ${ }^{13}$ Many studies have demonstrated its significant association with high-risk clinicopathological characteristics of PTC in overall analyses on tumors of all sizes. Importantly, this mutation is associated with a markedly increased rate of recurrence ${ }^{13}$ and even mortality ${ }^{14}$ of PTC. Multivariate analyses showed that the prognostic power of $B R A F$ mutation for PTC was independent of the classical clinicopathological risk factors. ${ }^{15,16}$ It was proposed that the examination of $B R A F$ mutation status could be helpful in optimizing the risk management of PTMC. ${ }^{5,13,15}$ This notion was supported by the recent demonstration in two Italian studies that $B R A F$ mutation in PTMC was associated with aggressive clinicopathological characteristics, such as extrathyroidal extension, lymph node metastasis, and advanced TNM stages. ${ }^{17,18}$ In this issue of the Journal, Lee and colleagues provide further evidence supporting the prognostic potential of $B R A F$ mutation in PTMC. ${ }^{19}$ In a Chinese cohort of patients with PTMC that were carefully characterized for clinicopathological characteristics, the authors demonstrate a significant association of $B R A F$ mutation with extrathyroidal extension, lymph node metastasis, and high TNM stages. BRAF mutation has been widely demonstrated to promote the upregulation of many tumor-promoting genes and the downregulation of tumorsuppressor genes; it has also been shown to be involved in the silencing of thyroid iodide-handling genes, impairing the susceptibility of PTC to radioiodine treatment. ${ }^{13}$ These 
$B R A F$ mutation-related molecular derangements are most probably the underlying mechanism for $B R A F$ mutationpromoted aggressiveness of PTMC as well. However, Lee and colleagues failed to find any case of "clinical" recurrence of PTMC over follow-up periods of 9 to 30 months, so the predictive role of $B R A F$ mutation for the recurrence of PTMC could not be directly examined. ${ }^{19}$ Still, it is not clear how the "clinical" recurrence was defined in this study. The relatively short time of follow-up might be one reason for the lack of any recurrence in this Chinese cohort of patients with PTMC. Another explanation for the lack of recurrence might be that the sensitive serum thyroglobulin testing and radioiodine body scan, which are routinely used for the detection of thyroid cancer persistence/recurrence in Western countries, were apparently not used by Lee and colleagues for the surveillance of PTC persistence/recurrence. Nevertheless, the highly significant association of $B R A F$ mutation with the classical high-risk clinicopathological factors in PTMC demonstrated by Lee and colleagues again strongly suggests that, as in conventional PTC, ${ }^{13} B R A F$ mutation is also a predictor for the aggressiveness of PTMC and may therefore indicate a poor prognosis, such as the persistence/recurrence of this cancer. Although one may have to wait for further studies on PTMC to directly test this hypothesis, that it is highly likely to be the case is suggested by the previous demonstration that $B R A F$ mutation predicted PTC recurrence in patients with TNM stage I and II diseases, a group that included many cases of PTMC. ${ }^{15,16}$ As PTMC is associated with an extremely low mortality rate, the core of the clinical effort in managing this cancer is to prevent, identify, and manage its recurrence. $B R A F$ mutation can be easily and reliably analyzed on fine-needle aspiration biopsy specimens. ${ }^{13}$ Preoperative information of $B R A F$ mutation status obtained through analysis of ultrasonography-guided fine-needle biopsy specimens of PTMC could be very valuable in guiding the management of this cancer at various stages, helping determine the extent of initial surgical treatment, the need for radioiodine ablation, and the level of vigilance in the subsequent follow-up of the patient.

Recent decades have seen a rapid rise in the incidence of thyroid cancer worldwide, which is virtually exclusively attributable to an increased diagnosis of PTC. ${ }^{20-22}$ Given that PTC accounts for $>80 \%$ of all thyroid cancers and that nearly $50 \%$ of the new cases of PTC are PTMC, ${ }^{20,21}$ a major challenge in today's thyroid cancer medicine is how to appropriately manage the already large and still increasing number of PTMC cases. Although the overall prevalence of $B R A F$ mutation in PTC is relatively high, around $45 \%$ on average, ${ }^{13}$ the prevalence of this mutation in PTMC is generally much lower in many parts of the world $^{17,18,23,24}$ and as low as $18 \%$ in PTMC of $<5 \mathrm{~mm}$ in size. $^{24}$ Excluding the areas in Korea where the BRAF mutation in PTC is somehow unusually high, the prevalence of $B R A F$ mutation in PTC with TNM stages I and II, which consist largely of small tumors, is around $30 \% .^{13}$ With the relatively low prevalence of $B R A F$ mutation in PTMC, it seems feasible to treat more aggressively the one-third of PTMC patients that are $B R A F$ mutation-positive and may be thus prone to a poor prognosis. The remaining cases (majority) of the PTMC patients that are $B R A F$ mutation-negative may be relatively conservatively managed unless indicated otherwise by other factors. The current risk management of PTMC is virtually exclusively based on clinicopathological criteria. By adding $B R A F$ mutation as a new dimension in risk stratification of PTMC, the appropriate extent of surgical and medical treatments of this cancer may now be better determined.

ACKNOWLEDGEMENT This work is supported by the NIH R0-1 grant CA113507-02 to the author.

\section{REFERENCES}

1. Lloyd R, DeLellis R, Heitz P, Eng C. World Health Organization classification of tumours: pathology and genetics of tumours of the endocrine organs. Lyon, France: IARC Press International Agency for Research on Cancer; 2004.

2. Witt RL. Initial surgical management of thyroid cancer. Surg Oncol Clin N Am. 2008;17:71-91.

3. Brown AP, Chen J, Hitchcock YJ, Szabo A, Shrieve DC, Tward JD. The risk of second primary malignancies up to three decades after the treatment of differentiated thyroid cancer. J Clin Endocrinol Metab. 2008;93:504-15.

4. Ito Y, Uruno T, Nakano K, Takamura Y, Miya A, Kobayashi K, et al. An observation trial without surgical treatment in patients with papillary microcarcinoma of the thyroid. Thyroid. 2003;13: 381-7.

5. Mazzaferri EL. Managing small thyroid cancers. JAMA. 2006;295:2179-82.

6. Mazzaferri EL. Management of low-risk differentiated thyroid cancer. Endocr Pract. 2007;13:498-512.

7. Hay ID. Management of patients with low-risk papillary thyroid carcinoma. Endocr Pract. 2007;13:521-33.

8. Yamashita H, Noguchi S, Murakami N, Toda M, Uchino S, Watanabe $\mathrm{S}$, et al. Extracapsular invasion of lymph node metastasis. A good indicator of disease recurrence and poor prognosis in patients with thyroid microcarcinoma. Cancer. 1999;86:842-9.

9. Sugitani I, Fujimoto Y. Symptomatic versus asymptomatic papillary thyroid microcarcinoma: a retrospective analysis of surgical outcome and prognostic factors. Endocr J. 1999;46:209-16.

10. Chow SM, Law SC, Chan JK, Au SK, Yau S, Lau WH. Papillary microcarcinoma of the thyroid-prognostic significance of lymph node metastasis and multifocality. Cancer. 2003;98:31-40.

11. Reddy RM, Grigsby PW, Moley JF, Hall BL. Lymph node metastases in differentiated thyroid cancer under $2 \mathrm{~cm}$. Surgery. 2006;140:1050-4.

12. Cappelli C, Castellano M, Braga M, Gandossi E, Pirola I, De Martino E, et al. Aggressiveness and outcome of papillary thyroid carcinoma (PTC) versus microcarcinoma (PMC): a mono-institutional experience. J Surg Oncol. 2007;95:555-60.

13. Xing M. BRAF mutation in papillary thyroid cancer: pathogenic role, molecular bases, and clinical implications. Endocr Rev. 2007;28:742-62. 
14. Elisei R, Ugolini C, Viola D, Lupi C, Biagini A, Giannini R, et al. BRAF(V600E) mutation and outcome of patients with papillary thyroid carcinoma: a 15 -year median follow-up study. J Clin Endocrinol Metab. 2008;93:3943-9.

15. Xing M, Westra WH, Tufano RP, Cohen Y, Rosenbaum E, Rhoden KJ, et al. BRAF mutation predicts a poorer clinical prognosis for papillary thyroid cancer. J Clin Endocrinol Metab. 2005;90:6373-9.

16. Kebebew E, Weng J, Bauer J, Ranvier G, Clark OH, Duh QY, et al. The prevalence and prognostic value of BRAF mutation in thyroid cancer. Ann Surg. 2007;246:466-70.

17. Rodolico V, Cabibi D, Pizzolanti G, Richiusa P, Gebbia N, Martorana A, et al. BRAF(V600E) mutation and p27(kip1) expression in papillary carcinomas of the thyroid $<J=1 \mathrm{~cm}$ and their paired lymph node metastases. Cancer. 2007;110:1218-26.

18. Lupi C, Giannini R, Ugolini C, Proietti A, Berti P, Minuto M, et al. Association of BRAF V600E mutation with poor clinicopathological outcomes in 500 consecutive cases of papillary thyroid carcinoma. J Clin Endocrinol Metab. 2007;92:4085-90.

19. Lee X, Gao M, Ji Y, Yu Y, Feng Y, Li Y, et al. Analysis of differential BRAF(V600E) mutational status in high aggressive papillary thyroid microcarcinoma. Ann Surg Oncol. 2009;2: $240-5$.

20. Leenhardt L, Grosclaude P, Cherie-Challine L. Increased incidence of thyroid carcinoma in France: a true epidemic or thyroid nodule management effects? report from the French thyroid cancer committee. Thyroid. 2004;14:1056-60.

21. Davies L, Welch HG. Increasing incidence of thyroid cancer in the United States, 1973-2002. JAMA. 2006;295:2164-7.

22. Ries LAG, Melbert D, Krapcho M, Stinchcomb DG, Howlader N, Horner MJ, et al., eds. SEER Cancer Statistics Review, 1975-2005, Bethesda, MD: National Cancer Institute. http://seer.cancer. gov/csr/1975_2005/, based on November 2007 SEER data submission, 2008.

23. Sedliarou I, Saenko V, Lantsov D, Rogounovitch T, Nambra H, Abrosimov A, et al. The BRAFT1796A transversion is a prevalent mutational event in human thyroid microcarcinoma. Int $J$ Oncol. 2004;25:1729-35.

24. Ugolini C, Giannini R, Lupi C, Salvatore G, Miccoli P, Proietti A, et al. Presence of BRAF V600E in very early stages of papillary thyroid carcinoma. Thyroid. 2007;17:381-8. 